where $(\mathbf{s})$ is

$$
\left(\begin{array}{lll}
1 & 0 & \overline{1} \\
0 & \overline{1} & 0 \\
0 & 0 & 1
\end{array}\right) .
$$

\section{References}

Norman, N. \& Mathisen, H. (1961a). Acta Chem. Scand. $15,1747-1754$.
Norman, N. \& Mathisen, H. (1961b). Acta Chem. Scand. $15,1755-1760$.

Norman, N. \& Mathisen, H. (1972). Acta Chem. Scand. 26, 3913-3916.

NyBuRG, S. C. \& Lüth, M. (1972). Acta Cryst. B28, 29922995.

Nyburg, S. C. \& Pickard, F. M. (1974). Acta Cryst. B30, $1885-1886$.

Nyburg, S. C. \& Potworowskr, J. A. (1973). Acta Cryst. B29, 347-352.

Acta Cryst. (1976). B32, 2293

\title{
Molecular Packing in Crystals of Phenoselenazine
}

\author{
By P. Villares, R. Jiménez-Garay, A. Conde and R. Márquez \\ Departamento de Optica, Sección de Física del Departamento de Investigaciones Físicas y Químicas \\ (Centro Coordinado del CSIC), Universidad de Sevilla, Spain
}

(Received 24 November 1975; accepted 6 January 1976)

\begin{abstract}
The crystal structure of phenoselenazine was solved by molecular-packing analysis. Trial models of the rigid molecule were oriented and positioned in the Cheshire cell. The refinement was carried out by structure-factor least-squares calculations using individual anisotropic temperature factors. The final discrepancy index was $R=0.051$ for 601 reflexions which were more than two standard deviations above background. The unit cell with $a=7.829(5), b=20.909$ (4) and $c=5.927$ (7) $\AA$ contains four molecules. The space group is $P 2_{1} 2_{1} 2_{1}$. The molecule has the same folded configuration as phenothiazine but is more open. The dihedral angle is $149 \cdot 6^{\circ}$.
\end{abstract}

\section{Introduction}

Semi-empirical potential functions, describing van der Waals interactions between pairs of non-bonded atoms, have been used in the structural analysis and the solution of the phase problem in molecular crystals (Kitaigorodsky, 1970; Giglio, 1970; Williams, 1972). The basic idea is that, neglecting the vibration energy and entropy, the non-bonded interaction energy in a crystal reaches a minimum when the molecular orientation and position are those experimentally observed.

The packing of a crystal can be obtained by minimizing the lattice energy as a function of molecular translations and rotations if the lattice constants and space group are known.

The molecular-packing analysis of phenoselenazine was undertaken as part of a series of structural analyses of organoselenium compounds. The crystal structure of 3,7-dichlorophenoselenazine (Bernier, Conde \& Márquez, 1974) has already been reported.

\section{Experimental}

Samples of phenoselenazine were supplied by Professor Pino (Departamento de Química Analítica of this University) and were recrystallized by evaporation of a solution in $\mathrm{CS}_{2}$.
Initially prepared crystals were extremely thin plates on (010), measuring only a few $\mu \mathrm{m}$ in thickness. Crystals having dimensions suitable for single-crystal work were finally obtained after a month of extremely slow evaporation at room temperature. Considerable difficulty was experienced in selecting and trimming crystals of this batch.

Weissenberg photographs were used to obtain the space group and preliminary unit-cell dimensions. Accurate lattice constants were obtained by a leastsquares fit to 20 reflexions. The crystal data are summarized in Table 1.

\section{Table 1. Crystal data for phenoselenazine}

$$
\begin{array}{ll}
a=7.829(5) \AA & \text { M.W. } 246 \\
b=20.909(4) & \text { m.p. } 468 \mathrm{~K} \\
c=5.927(7) & D_{x}=1.70 \times 10^{3} \mathrm{~kg} \mathrm{~m}^{-3} \\
V=970 \cdot 2(7) \AA^{3} & \text { Space group } P 2_{1} 2_{1} 2_{1} \\
\lambda(\text { Mo } K \alpha)=0.7107 \AA & Z=4
\end{array}
$$

A Nonius CAD-4 four-circle automatic diffractometer and graphite-monochromated Mo $K \alpha$ radiation were used with a scintillation detector and pulseheight discrimination. Two reflexions were monitored periodically during the data-collection process. Subsequent analysis of these reflexions indicated no crystal decomposition during the time required to collect the intensities. Reflexions were collected in the range 
$1.5<\theta<25^{\circ}$ in the ZIG-ZAG scan mode. Of this total, 601 reflexions were considered observed by the criterion $I>2 \sigma(I)$ and were used in the refinement calculations. The structure amplitudes were obtained after the usual Lorentz and polarization reduction. No correction for absorption was applied because of the small size of the crystal used.

\section{Molecular-packing analysis}

The coordinates of a trial model (Table 2) were calculated from accepted values of bond lengths and angles. The dihedral angle between the planes through the two molecular halves was taken as $150^{\circ}$, in agreement with the observed value of $146.5^{\circ}$ in 3,7-dichlorophenoselenazine. Hydrogen atoms were included because hydrogen interactions are critical in determining molecular interactions in packing calculations.

\section{Table 2. Trial model coordinates $(\AA)$}

\begin{tabular}{|c|c|c|c|}
\hline & $x$ & $y$ & $z$ \\
\hline $\mathrm{Se}$ & 0.00 & 0.00 & $2 \cdot 13$ \\
\hline $\mathbf{N}$ & 0.00 & 0.00 & $-1 \cdot 22$ \\
\hline$C(1)$ & $0 \cdot 38$ & $-1 \cdot 42$ & 0.89 \\
\hline $\mathrm{C}(2)$ & 0.72 & -2.69 & 1.46 \\
\hline$C(3)$ & 1.02 & $-3 \cdot 82$ & 0.53 \\
\hline C(4) & 0.97 & $-3 \cdot 60$ & -0.88 \\
\hline $\mathrm{C}(5)$ & 0.62 & $-2 \cdot 30$ & $-1 \cdot 42$ \\
\hline C(6) & 0.32 & $-1 \cdot 19$ & -0.52 \\
\hline$C(7)$ & 0.32 & $1 \cdot 19$ & 0.52 \\
\hline C(8) & 0.62 & $2 \cdot 30$ & -1.42 \\
\hline $\mathrm{C}(9)$ & 0.97 & $3 \cdot 60$ & -0.88 \\
\hline$C(10)$ & 1.02 & $3 \cdot 82$ & 0.53 \\
\hline C(11) & 0.72 & 2.69 & 1.46 \\
\hline $\mathrm{C}(12)$ & 0.38 & 1.42 & 0.89 \\
\hline $\mathrm{H}(2)$ & 0.76 & -2.83 & $2 \cdot 45$ \\
\hline $\mathrm{H}(3)$ & 1.26 & -4.68 & 0.95 \\
\hline $\mathrm{H}(4)$ & $1 \cdot 17$ & $-4 \cdot 38$ & -1.50 \\
\hline $\mathrm{H}(5)$ & 0.58 & $-2 \cdot 15$ & -2.40 \\
\hline $\mathrm{H}(\mathrm{N})$ & 0.00 & 0.00 & $-2 \cdot 23$ \\
\hline $\mathrm{H}(8)$ & 0.58 & $2 \cdot 15$ & $-2 \cdot 40$ \\
\hline $\mathrm{H}(9)$ & $1 \cdot 17$ & 4.38 & -1.50 \\
\hline $\mathrm{H}(10)$ & 1.26 & 4.68 & 0.95 \\
\hline $\mathrm{H}(11)$ & 0.76 & $2 \cdot 83$ & 2.45 \\
\hline
\end{tabular}

The variables considered were six rigid-body rotations and translations for the molecule in the asymmetric unit. An obvious way to generate starting models for the packing analysis is to use a grid for the angles and translations sufficiently fine to ensure convergence. The space-group symmetry may be used to reduce the number of trial packing models (Hirshfeld, 1968). The Cheshire group is $P m m m$, and the molecular centre of the reference molecule may be placed in the range $0 \leq x \leq a / 4$, $0 \leq y \leq b / 4,0 \leq z \leq c / 4$. Using 12 orientation matrices, we explored this volume on a $2 \AA$ grid for the position of the molecular centre.

In the first stage the repulsive lattice energy is approximated by the sum of the quadratic non-bonded interatomic potential functions and the lattice energy sum is minimized by full-matrix least-squares calcula- tions, using the computer program PCK5 (Williams, 1969). In this program the quantity minimized is

$$
E_{r}=\frac{1}{2} \sum w\left(d_{o}-d_{c}\right)^{2}, \quad d_{c}<d_{o},
$$

where the sum is over all non-bonded interatomic contacts of the reference molecule with surrounding molecules. The $w$ and $d_{o}$ values used are detailed in Table 3 and were obtained by fitting the first derivatives of $(\exp -6)$ and quadratic functions (Williams, 1969). Five of the trial models converged to a structure (model I) with the lowest packing index $\left(2 E_{r}=\right.$ $5.8 \mathrm{~kJ} \mathrm{~mol}^{-1}$ ). This value is in agreement with the assumption of a constant repulsive contribution for each hydrogen in the structure of 0.4 to $1.1 \mathrm{~kJ} \mathrm{~mol}^{-1}$ per hydrogen atom (Williams, 1969). The molecular orientation matrix and the translation of the centre of the molecule are:

$$
\begin{aligned}
& \mathbf{R}_{\mathbf{I}}=\left(\begin{array}{rrr}
0.7989 & -0.3238 & -0.5069 \\
0.3799 & 0.9250 & 0.0079 \\
0.4663 & -0.1989 & 0.8620
\end{array}\right) \\
& \mathbf{T}_{\mathrm{I}}=\left(\begin{array}{lll}
2 \cdot 19 & 2.98 & 1.57
\end{array}\right) \AA .
\end{aligned}
$$

The other trial models converged to false minima with

\begin{tabular}{|c|c|c|}
\hline Interaction & $d_{o}(\AA)$ & $w\left(\mathrm{~kJ} \mathrm{~mol}^{-1} \AA^{-2}\right)$ \\
\hline $\mathrm{Se} \cdots \mathrm{Se}$ & 3.93 & $20 \cdot 3$ \\
\hline $\mathrm{Se} \cdots \mathrm{N}$ & $3 \cdot 79$ & $9 \cdot 7$ \\
\hline $\mathrm{Se} \cdot \mathrm{C}$ & $3 \cdot 80$ & $8 \cdot 3$ \\
\hline $\mathrm{Se} \cdots \mathrm{H}$ & $3 \cdot 32$ & $7 \cdot 0$ \\
\hline $\mathrm{N} \cdots \mathrm{N}$ & $3 \cdot 62$ & $10 \cdot 9$ \\
\hline $\mathrm{N} \cdots \mathrm{C}$ & $3 \cdot 59$ & $6 \cdot 5$ \\
\hline $\mathrm{N} \cdot \cdots \mathrm{H}$ & $2 \cdot 76$ & $5 \cdot 7$ \\
\hline $\mathrm{C} \cdots \mathrm{C}$ & $3 \cdot 62$ & $8 \cdot 8$ \\
\hline $\mathrm{C} \cdots \mathrm{H}$ & $2 \cdot 99$ & $7 \cdot 7$ \\
\hline $\mathbf{H} \cdot \vec{H}$ & $2 \cdot 83$ & $5 \cdot 2$ \\
\hline
\end{tabular}
higher values of the repulsive energy.

Table 3. Potential parameters for quadratic functions

Since no attractions are considered, there are relatively few terms in the lattice sum, and $P C K 5$ is very fast in execution. A greater accuracy can be obtained if the intermolecular lattice energy of the crystal is approximated by a pairwise sum of the $(\exp -6)$ nonbonded interatomic potential functions. We have used the computer program PCK6 (Williams, 1972) in which increased speed of calculation of the lattice sums is achieved by a convergence acceleration technique.

The starting set of coordinates in this second stage was that obtained in the $P C K 5$ calculation. The lattice sum limit was taken as $5 \cdot 0 \AA$ for all interactions. Potential functions in the Buckingham (exp -6) form have been used to describe van der Waals interactions between pairs of nonbonded atoms. Coefficients fitted by Williams (1967) for C $\cdots \mathrm{C}, \mathrm{C} \cdots \mathrm{H}$ and $\mathrm{H} \cdots \mathrm{H}$ and by Govers (1975) for N ‥N have been used. For the selenium atom, potentials based on kryptonkrypton interactions and reported elsewhere (Villares, Jiménez-Garay, Conde \& Márquez, 1976) have been employed. 
A Gauss-Newton cycle of refinement gave model II characterized by $\mathbf{R}_{\mathrm{II}}, \mathbf{T}_{\mathrm{II}}$ :

$$
\begin{aligned}
\mathbf{R}_{\text {II }} & =\left(\begin{array}{rrr}
0.8076 & -0.3109 & -0.5011 \\
0.3653 & 0.9308 & 0.0111 \\
0.4630 & -0.1920 & 0.8653
\end{array}\right) \\
\mathbf{T}_{\text {II }} & =\left(\begin{array}{lll}
2.19 & 2.98 & 1.57)
\end{array} .\right.
\end{aligned}
$$

All the sets of potentials give a good agreement with respect to the experimental unit-cell dimensions of phenoselenazine and no significant differences in the resulting coordinates were encountered.

\section{Refinement and discussion}

Model II, excluding the hydrogen atoms, was refined by structure-factor least-squares methods. The fullmatrix program ORFLS (Busing, Martin \& Levy, 1962) was used. Initially, individual isotropic temperature factors were used in the calculations and $R$ dropped to 0.087 for all reflexions. Scattering factors were from International Tables for X-ray Crystallography (1962) and anomalous scattering corrections for the selenium atom were applied (Cromer, 1965). In the last cycles anisotropic refinement was carried out and the final $R$ was 0.051 . Table 4 lists the positional coordinates and anisotropic temperature factors.*

Bond lengths and angles in the molecule of phenoselenazine are listed in Table 5 . The observed values of $1.90 \AA$ for the $\mathrm{Se}-\mathrm{C}$ distances and $97^{\circ}$ for the $\mathrm{C}-\mathrm{Se}-\mathrm{C}$ angles may be compared with the values reported in other organoselenium compounds. These values are analogous to those found in 3,7-dichlorophenoselenazine (Bernier, Conde \& Márquez, 1974).

The mean bond length $\mathrm{N}-\mathrm{C}$ of $1.41 \AA$ and the angle $\mathrm{C}-\mathrm{N}-\mathrm{C}$ of $122^{\circ}$ agree with $s p^{2}$ hybridization.

The molecule is not planar but consists of two planar halves folded along the $\mathrm{N}-\mathrm{Se}$ axis, with a

* A list of structure factors has been deposited with the British Library Lending Division as Supplementary Publication No. SUP 31609 (3 pp.). Copies may be obtained through The Executive Secretary, International Union of Crystallography, 13 White Friars, Chester CH1 1NZ, England.
Table 5. Bond lengths and angles

(a) Bond lengths in $\AA(\sigma=0.02 \AA)$

$\begin{array}{llll}\mathrm{Se}-\mathrm{C}(1) & 1.89 & \mathrm{~N}-\mathrm{C}(6) & 1.39 \\ \mathrm{Se}-\mathrm{C}(12) & 1.89 & \mathrm{~N}-\mathrm{C}(7) & 1.43 \\ \mathrm{C}(1)-\mathrm{C}(2) & 1.36 & \mathrm{C}(7)-\mathrm{C}(8) & 1.39 \\ \mathrm{C}(2)-\mathrm{C}(3) & 1.45 & \mathrm{C}(8)-\mathrm{C}(9) & 1.40 \\ \mathrm{C}(3)-\mathrm{C}(4) & 1.35 & \mathrm{C}(9)-\mathrm{C}(10) & 1.44 \\ \mathrm{C}(4)-\mathrm{C}(5) & 1.39 & \mathrm{C}(10)-\mathrm{C}(11) & 1.36 \\ \mathrm{C}(5)-\mathrm{C}(6) & 1.43 & \mathrm{C}(11)-\mathrm{C}(12) & 1.40 \\ \mathrm{C}(1)-\mathrm{C}(6) & 1.42 & \mathrm{C}(7)-\mathrm{C}(12) & 1.40\end{array}$

(b) Bond angles in degrees $\left(\sigma=1^{\circ}\right)$

$\begin{array}{lrll}\mathrm{C}(1)-\mathrm{Se}-\mathrm{C}(12) & 97 & \mathrm{C}(1)-\mathrm{C}(2)-\mathrm{C}(3) & 118 \\ \mathrm{Se}-\mathrm{C}(12)-\mathrm{C}(17) & 120 & \mathrm{C}(2)-\mathrm{C}(3)-\mathrm{C}(4) & 121 \\ \mathrm{Se}-\mathrm{C}(12)-\mathrm{C}(11) & 121 & \mathrm{C}(3)-\mathrm{C}(4)-\mathrm{C}(5) & 121 \\ \mathrm{Se}-\mathrm{C}(1)-\mathrm{C}(6) & 117 & \mathrm{C}(4)-\mathrm{C}(5)-\mathrm{C}(6) & 119 \\ \mathrm{Se}-\mathrm{C}(1)-\mathrm{C}(2) & 120 & \mathrm{C}(1)-\mathrm{C}(6)-\mathrm{C}(5) & 118 \\ \mathrm{C}(6)-\mathrm{N}-\mathrm{C}(7) & 122 & \mathrm{C}(8)-\mathrm{C}(7)-\mathrm{C}(12) & 120 \\ \mathrm{~N}-\mathrm{C}(7)-\mathrm{C}(8) & 120 & \mathrm{C}(7)-\mathrm{C}(8)-\mathrm{C}(9) & 120 \\ \mathrm{~N}-\mathrm{C}(7)-\mathrm{C}(12) & 120 & \mathrm{C}(8)-\mathrm{C}(9)-\mathrm{C}(10) & 119 \\ \mathrm{~N}-\mathrm{C}(6)-\mathrm{C}(1) & 124 & \mathrm{C}(9)-\mathrm{C}(10)-\mathrm{C}(11) & 119 \\ \mathrm{~N}-\mathrm{C}(6)-\mathrm{C}(5) & 118 & \mathrm{C}(10)-\mathrm{C}(11)-\mathrm{C}(12) & 122 \\ \mathrm{C}(2)-\mathrm{C}(1)-\mathrm{C}(6) & 122 & \mathrm{C}(7)-\mathrm{C}(12)-\mathrm{C}(11) & 119\end{array}$

dihedral angle of $149 \cdot 7^{\circ}$; similar to the value reported in dichlorophenoselenazine. This conformation is a normal feature in molecules in which the two atoms that bound the rings have different hybridization. There seems to be no packing influence to force this angle to differ from its intrinsic value, and it therefore seems that this degree of folding represents the configuration of free phenoselenazine.

The two benzene rings are planar, as expected; Table 6 contains detailed information.

Table 6. Deviations $(\AA)$ of the atoms from least-squares planes

(a) Plane $A: 0.6945 x+0.5908 y+0.4106 z=3.9078$

$\begin{array}{lrlr}\mathrm{C}(1) & -0.00 & \mathrm{C}(5) & 0.02 \\ \mathrm{C}(2) & 0.03 & \mathrm{C}(6) & 0.02 \\ \mathrm{C}(3) & -0.02 & \mathrm{Se}^{*} & -0.19 \\ \mathrm{C}(4) & -0.00 & \mathrm{~N}^{*} & -0.07\end{array}$

(b) Plane $B: 0 \cdot 8724 x+0 \cdot 1055 y+0 \cdot 4773 z=2 \cdot 8820$

$\begin{array}{lrlr}C(7) & 0.02 & \mathrm{C}(11) & 0.01 \\ \mathrm{C}(8) & -0.00 & \mathrm{C}(12) & -0.02 \\ \mathrm{C}(9) & -0.01 & \mathrm{Se}^{*} & -0.18 \\ \mathrm{C}(10) & 0.01 & \mathrm{~N}^{*} & 0.04\end{array}$

* Atoms omitted from the calculation of the least-squares plane.

\begin{tabular}{|c|c|c|c|c|c|c|c|c|c|}
\hline & $x$ & $y$ & $z$ & $\beta_{11}$ & $\beta_{22}$ & $\beta_{33}$ & $\beta_{12}$ & $\beta_{13}$ & $\beta_{23}$ \\
\hline $\mathrm{Se}$ & $1282(2)$ & $1390(1)$ & $5372(3)$ & $143(3)$ & $25(1)$ & $204(6)$ & $9(1)$ & $58(4)$ & $7(1)$ \\
\hline N & $3428(16)$ & $1410(7)$ & 939 (19) & $172(25)$ & $26(3)$ & $216(41)$ & $13(9)$ & $-16(25)$ & $-6(12)$ \\
\hline$C(1)$ & $3162(18)$ & $857(7)$ & $4638(29)$ & $143(26)$ & $24(4)$ & $227(48)$ & $-2(8)$ & $17(36)$ & $-15(14)$ \\
\hline$C(2)$ & $3655(25)$ & $382(7)$ & $6057(27)$ & $192(32)$ & $25(4)$ & $303(59)$ & $-8(12)$ & $-86(45)$ & 33 (13) \\
\hline C(3) & $4939(20)$ & $-67(7)$ & $5259(36)$ & $162(29)$ & $20(4)$ & $432(74)$ & $-5(10)$ & $-125(48)$ & $-3(16)$ \\
\hline C(4) & $5712(22)$ & $9(8)$ & $3244(27)$ & $189(34)$ & $25(4)$ & $191(55)$ & $-5(10)$ & $34(37)$ & $13(13)$ \\
\hline$C(5)$ & 5260 (19) & $513(7)$ & $1808(26)$ & $166(30)$ & $15(3)$ & $251(54)$ & $-3(10)$ & $12(37)$ & $-8(12)$ \\
\hline C(6) & $3913(23)$ & $936(7)$ & $2456(25)$ & $185(32)$ & $17(3)$ & $210(47)$ & $1(10)$ & $3(38)$ & $3(11)$ \\
\hline$C(7)$ & 2905 (19) & $2035(7)$ & $1650(24)$ & $164(26)$ & $23(4)$ & 155 (51) & $8(9)$ & $-62(31)$ & $-10(12)$ \\
\hline$C(8)$ & $3271(18)$ & $2561(7)$ & $290(30)$ & $127(30)$ & $23(4)$ & $231(52)$ & $3(8)$ & $-10(34)$ & $-1(12)$ \\
\hline $\mathrm{C}(9)$ & $2773(22)$ & $3179(8)$ & $967(36)$ & $162(32)$ & $25(5)$ & $430(82)$ & $-12(11)$ & $3(41)$ & $27(16)$ \\
\hline$C(10)$ & $1902(22)$ & $3259(9)$ & $3088(34)$ & $167(32)$ & $26(5)$ & $358(69)$ & $-1(11)$ & $-53(42)$ & $-1(16)$ \\
\hline$C(11)$ & $1539(21)$ & $2736(8)$ & $4364(29)$ & $169(34)$ & $25(4)$ & $285(54)$ & $8(11)$ & $-21(40)$ & $-40(16)$ \\
\hline$C(12)$ & $1982(20)$ & $2113(8)$ & $3675(28)$ & $104(24)$ & $33(5)$ & $193(47)$ & $2(10)$ & $-38(32)$ & $10(13)$ \\
\hline
\end{tabular}

Table 4. Atomic coordinates and thermal parameters $\left(\times 10^{4}\right)$ 
The mean bond length $\mathrm{C}-\mathrm{C}$ in the phenyl rings is $1.40 \AA$ and the average $\mathrm{C}-\mathrm{C}-\mathrm{C}$ angle is $119.8^{\circ}$. The significant deviations are $0.02 \AA$ and $1^{\circ}$ respectively. These standard deviations are significantly high, probably as a result of the low number of observed reflexions. On the other hand the accuracy of the diffraction data is limited by the characteristics of the crystal.

The packing modes of the molecules as viewed down $\mathbf{a}$ and $\mathbf{c}$ are shown in Figs. 1 and 2. The crystal cohesion is due to a large number of van der Waals contacts. Table 7 contains intermolecular contacts less than $4 \AA$.

Table 7. Intermolecular contacts less than $4 \AA(\sigma=0.02 \AA)$

\begin{tabular}{|c|c|c|c|c|c|}
\hline$\cdot \mathrm{N}$ & $(i, 001)$ & $2 \cdot 75$ & $C(2) \cdots C(6)$ & $(\mathrm{ii}, 000)$ & $3 \cdot 7$ \\
\hline$\cdot \mathrm{C}(4)$ & (ii, 000$)$ & $3 \cdot 73$ & $C(2) \cdots C(10)$ & $(\mathrm{iii}, 000)$ & \\
\hline $\mathrm{Se} \cdots \mathrm{C}(9)$ & (iii, $\overline{1} 00$ ) & $3 \cdot($ & $C(3) \cdots C(6)$ & (ii, 000$)$ & 3. \\
\hline $\mathrm{Se} \cdots \mathrm{C}(10)$ & (iii, 100$)$ & $3 \cdot 62$ & $C(3) \cdots C(4)$ & (ii, 100) & $3 \cdot 87$ \\
\hline$N \cdots C(1)$ & $(\mathrm{i}, 00 \overline{1})$ & $3 \cdot 5$ & $C(3) \cdots C(5)$ & (ii, 100) & .98 \\
\hline$\cdot \mathrm{C}(2)$ & $(\mathrm{i}, 00 \overline{1})$ & $3 \cdot$ & $C(4) \cdots C(5)$ & $0)$ & .98 \\
\hline$\cdot C(3)$ & (ii, 001) & 5 & $C(5) \cdots C(9)$ & (iii, 001) & 3.1 \\
\hline$\cdot \mathrm{C}(9)$ & $(\mathrm{i}, 001)$ & $3 \cdot 69$ & $C(6) \cdots C(10)$ & (iii, 000) & $3 \cdot 9$ \\
\hline$\cdot \mathrm{C}(10)$ & (iii, 001) & 3.6 & $\cdot C(11)$ & (iii, 000 ) & \\
\hline$\cdot C(2)$ & (ii, 00 & $3 \cdot$ & $\cdot C(8)$ & (iii, T01) & 90 \\
\hline - $\mathrm{C}(3)$ & (ii, & 2 & $C(7) \cdots C(11)$ & (iii, & $3 \cdot 73$ \\
\hline$C(1) \cdots C(10)$ & (iii, 000) & 3. & $C(8) \cdots C(8)$ & (iii, 001 ) & $3 \cdot 9$ \\
\hline$C(1) \cdots C(11)$ & (iii, 001) & $4 \cdot 00$ & $\mathrm{C}(8) \cdots \mathrm{C}(8)$ & (iii, $\overline{1} 0 \overline{1}$ & $3 \cdot 9$ \\
\hline$C(2) \cdots C(5)$ & $(\mathrm{i}, 00 \overline{1})$ & $3 \cdot$ & $\mathrm{C}(8) \cdots \mathrm{C}(9)$ & (iii, 0 & $3 \cdot 9$ \\
\hline$C(2) \cdots C(6)$ & $(\mathrm{i}, 001)$ & 3. & $C(10)$ & 101) & 8 \\
\hline $\mathrm{C}(2) \cdots \mathrm{C}(3)$ & (ii, 000) & $3 \cdot 82$ & $C(8) \cdots C(11)$ & (iii, 001) & $3 \cdot 8$ \\
\hline $\mathrm{C}(2) \cdots \mathrm{C}(2)$ & (ii, 001) & $3 \cdot$ & $C(8) \cdots C(12)$ & (iii, 001) & 3 . \\
\hline$C(2) \cdots C(2)$ & $(\mathrm{ii}, 000)$ & & $\cdot \mathrm{C}(11)$ & $(i, 001)$ & $3 \cdot 70$ \\
\hline$C(2) \cdots C(4)$ & (ii, & & $C(11) \cdots C(12)$ & (iii, 100) & $3 \cdot 76$ \\
\hline$C(2) \cdots C(5)$ & (ii, & & & & \\
\hline
\end{tabular}
(i) $x, y, z$; (ii) $\frac{1}{2}-x, \bar{y}, \frac{1}{2}+z$; (iii) $\frac{1}{2}+x, \frac{1}{2}-y, \bar{z}$.

All the calculations were performed on the DCT 2000 of Centro de Cálculo de la Universidad de Sevilla, connected to a Univac 1108 computer.

The authors thank $\operatorname{Dr}$ D. E. Williams for providing programs $P C K 5$ and $P C K 6$ and EnrafNonius for the diffraction-data collection on a CAD-4 diffractometer. The present work forms part of the Doctoral Thesis of one of us (P.V.).

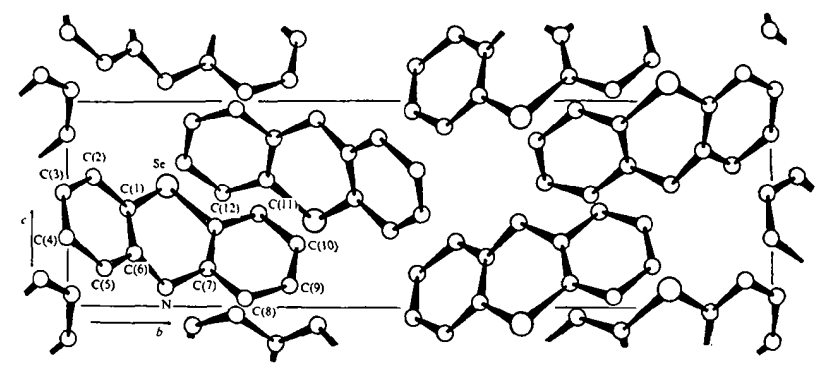

Fig. 1. The structure as viewed down [100].

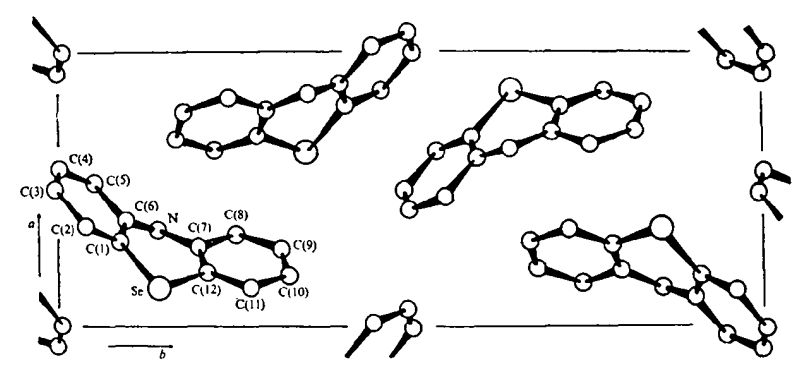

Fig. 2. A view of the structure down [001].

\section{References}

Bernier, F., Conde, A. \& Márquez, R. (1974). Acta Cryst. B30, 1332-1335.

Busing, W. R., Martin, K. O. \& Levy, H. A. (1962). ORFLS. Oak Ridge National Laboratory Report ORNLTM-305.

Cromer, D. T. (1965). Acta Cryst. 18, 17-23.

Giglio, E. (1970). Z. Kristallogr. 131, 385-396.

Govers, H. A. J. (1975). Acta Cryst. A 31, 380-385.

Hirshreld, F. L. (1968). Acta Cryst. A24, 301-311.

International Tables for X-ray Crystallography (1962). Vol. III, pp. 202-216. Birmingham: Kynoch Press.

Kitaigorodsky, A. I. (1970). Advanc. Struct. Res. Diff. Meth. 3, 173-248.

Villares, P., Jiménez-Garay, R., Conde, A. \& Márquez, R. (1976). In the press.

Williams, D. E. (1967). J. Chem. Phys. 47, 4680-4684.

Williams, D. E. (1969). Acta Cryst. A 25, 464-470.

Williams, D. E. (1972). Acta Cryst. A28, 629-635. 